\title{
Assessment of Intelligence Quotient in School-Aged Children Who Are Breastfed Versus Artificial-Fed
}

\author{
Hisham Samy Abdel-Hameed, Ehab M. Rasheed, Shimaa Adel Ali Yousef*
}

Department of Pediatrics, Faculty of Medicine, Zagazig University, Zagazig, Egypt

*Corresponding author: Shimaa Adel Ali Yousef, Telephone: +201024683929, E mail: mosad8rashed@gmail.com

\begin{abstract}
Background: Food can affect the brain throughout the entire life cycle. Cognition refers to the mental processes involved in the acquisition of knowledge and the integration of these processes into responses such as the intelligence quotient (IQ).

Objective: The purpose of this study was to compare intelligence quotient of children aged 6-10 years who were breastfed in their post-natal life versus those who were not exposed to breastfeeding.

Patients and methods: A case control study was conducted on 56 children in Zagazig University Children Hospital, during the period from October 2018 to March 2019. They were divided into two groups. Group I: 28 healthy children who were exclusively breastfed. Group II: 28 healthy children who were artificially-fed. All cases were subjected to: A constructed questionnaire assessing breastfeeding practices during the first two years as well as the current health status over the past years and current and past behavioral disorders. Clinical examination was done. Dietary assessment was done to assess current feeding and food intake practices. Special test; Wechsler and Primary Scale of Intelligence was done for all participants to assess the cognitive functions.

Results: This study showed that, higher IQ in the breastfed group as compared to the artificially-fed group. Conclusion: Cognitive function of the child is increased with the increased duration of exclusive breastfeeding up to six months of age. The education of the mother positively influenced the IQ among children who were exclusively breastfed for 6 months but not the other groups.
\end{abstract}

Keywords: Intelligence quotient, Breastfed versus, Artificial fed.

\section{INTRODUCTION}

Nutrition will affect the brain over the life cycle, with important consequences for mental health and degenerative diseases. Many aspects of nutrition, from whole diets to particular nutrients, influence brain structure and function. Cognition refers to the mental processes involved in the processing of information and the incorporation of these processes into reactions such as learning, attention, memory, intellect (IQ) and consciousness ${ }^{(\mathbf{1})}$.

Adequate supply of nutrients, beginning at the early stages of life, is essential to ensuring healthy physical and mental growth and long-term health. Low availability or access to food of sufficient nutritional quality or exposure to conditions that hinder the absorption and use of nutrients has contributed to large parts of the world's population being undernourished, poor in vitamin and mineral content, or overweight and obese, with major variations between population groups. Such conditions are frequently present at the same time and interconnected. Such developmental processes build on each other over time such that a small change in either of the processes can have a significant and long-lasting effect on brain structure and function. Postnatal nutrition, in particular breastfeeding, may not only control brain growth, but may also influence the child's developmental milestones ${ }^{(2)}$.
It is important to know if slower infant weight gain is associated with weaker cognition in healthy infant populations, since rapid weight gain can cause some harm, including increased risk of obesity and related disorders later in life ${ }^{(3)}$.

Breast milk provides optimal nutrition for a growing infant, with compositional changes adapted to the changing needs of the baby. Human milk contains ample minerals and nutrients for the first six months of life.

There is a clear association between breastfeeding and cognitive development in babies. This cognitive capacity is measured by IQ tests. Breastfeeding is important for brain growth and intelligence because it includes high amounts of long chain polyunsaturated fatty acids such as docosahexaenoic acid (D.H.A) and arachidonic acid (A.A). This also contains cholesterol, amino acids such as taurine, and even lactose broken down into glucose and galactose in the body. They are all essential nutrients for brain and central organ tissue ${ }^{(4)}$.

\section{AIM OF THE WORK}

The aim of this study was to study the association between optimal infant feeding practices and the cognitive function in school aged children. 


\section{SUBJECTS AND METHODS}

A case control study was conducted on 56 healthy child aged 6 to 10 years attending Zagazig University Children Hospital, during the period from October 2018 to march 2019. They were divided into two groups. Group I: included 28 healthy children who were exclusively breastfed comprising 15 males and 13 females. Group II: included 28 healthy children who were artificially fed comprising 15 males and 13 females. All cases were subjected to: A constructed questionnaire assessing breastfeeding practices during the first two years as well as the current and past health status over the past years and current and past behavioral disorders. Clinical examination was done. Dietary assessment was done to assess current feeding and food intake practices. Special test for the intelligence: Wechsler and Primary Scale of Intelligence was done for all participants to assess the cognitive functions.

Inclusion criteria: Apparently healthy school-aged children 6-10 years old attending the outpatient clinic or nursery; with normal speech as regards their age. Children who were exclusively breastfed or who were exclusively formula-fed.

Exclusion criteria: Children who were breastfed and artificial fed. Children with neurological and psychological diseases (as mental retardation, cerebral palsy, etc..). Children with chronic diseases. Patients with diseases that may affect their attention.

\section{Special test for the intelligence:}

The Intelligence quotient (IQ) was measured by the Wechsler and Primary Scale of Intelligence (WPPSI), which was done for all participants to assess the cognitive functions. The WISC Test (Wechsler
Intelligence Scale for Infants) is an IQ test provided by school districts and psychologists to children between the ages of 6 and 16. The purpose of the exam was to explain whether or not the child is gifted, as well as to assess the cognitive ability and weakness of the pupil was obtained from the patient's parents ${ }^{(5)}$.

\section{Ethical approval:}

Approval for the study was obtained from the Department of Pediatrics, University Hospitals of Zagazig, following the approval of the Institutional Review Board (IRB). The research was carried out in compliance with the World Medical Association's Code of Ethics (Helsinki Declaration) of humanrelated studies.

\section{Statistical analysis}

The statistical analysis of the data was carried out using the Excel system for data and the SPSS program version 16 . In order to check the normality of data distribution, the K-S (Kolmogorov-Smirnov) test was done. Data are presented as means $( \pm$ ) SD and range for quantitative data and in number and percentage for qualitative data. For the quantitative data, the independent Student t-test was used to compare the two classes.

Chi square test was used for qualitative data. Spearman correlation coefficient was used to check the relationship between variable. $\mathrm{P}$ was considered significant if $<$ or $=0.05$ at 95 percent confidence interval.

\section{RESULTS}

All the checked data showed to be parametric. Table (1) showed that there was non-significant difference between the studied groups as regard age family size, order in family and sex.

Table (1): Demographic data in between the studied groups

\begin{tabular}{|c|c|c|c|c|c|c|}
\hline Variable & \multicolumn{2}{|c|}{$\begin{array}{l}\text { Breastfed } \\
\quad(\mathbf{n}=\mathbf{2 8})\end{array}$} & \multicolumn{2}{|c|}{$\begin{array}{l}\text { Artificial-fed } \\
\qquad(\mathbf{n}=\mathbf{2 8})\end{array}$} & t-test & P value \\
\hline \multicolumn{7}{|l|}{ Age: } \\
\hline $\begin{array}{c}\text { Mean } \pm \text { SD } \\
\text { Range }\end{array}$ & \multicolumn{2}{|c|}{$\begin{array}{c}7.92 \pm 1.16 \\
6.1-9.9\end{array}$} & \multicolumn{2}{|c|}{$\begin{array}{c}7.71 \pm 1.29 \\
6-9.8\end{array}$} & 0.640 & 0.524 \\
\hline \multicolumn{7}{|c|}{ Family size including parents: } \\
\hline $\begin{array}{c}\text { Mean } \pm \text { SD } \\
\text { Range }\end{array}$ & \multicolumn{2}{|c|}{$\begin{array}{c}4.82 \pm 1.28 \\
3-7 \\
\end{array}$} & \multicolumn{2}{|c|}{$\begin{array}{c}4.68 \pm 1.46 \\
3-8\end{array}$} & 0.382 & 0.704 \\
\hline \multicolumn{7}{|l|}{ Order in family : } \\
\hline $\begin{array}{c}\text { Mean } \pm \text { SD } \\
\text { Range }\end{array}$ & \multicolumn{2}{|c|}{$\begin{array}{c}3.1 \pm 0.5 \\
1-5\end{array}$} & \multicolumn{2}{|c|}{$\begin{array}{c}3.2 \pm 0.8 \\
1-5\end{array}$} & -0.56 & 0.577 \\
\hline & No. & $\%$ & No. & $\%$ & $\chi^{2}$ & P value \\
\hline \multicolumn{7}{|l|}{ Sex: } \\
\hline $\begin{array}{l}\text { Male } \\
\text { Female }\end{array}$ & $\begin{array}{l}15 \\
13\end{array}$ & $\begin{array}{l}53.6 \\
46.4\end{array}$ & $\begin{array}{l}15 \\
13\end{array}$ & $\begin{array}{l}53.6 \\
46.4\end{array}$ & 0.00 & 1 \\
\hline
\end{tabular}


Table (2) showed that there was no significant difference between the studied groups as regard weight, height and mid arm circumference.

Table (2): Anthropometric measurements of the studied groups

\begin{tabular}{|c|c|c|c|c|}
\hline Variable & $\begin{array}{c}\text { Breastfed } \\
(\mathbf{n = 2 8})\end{array}$ & $\begin{array}{c}\text { Artificial-fed } \\
(\mathbf{n = 2 8})\end{array}$ & t-test & P value \\
\hline Weight: & $\begin{array}{c}17.5 \pm 2.8 \\
12-20\end{array}$ & $\begin{array}{c}18.2 \pm 2.7 \\
11-19\end{array}$ & 0.952 & 0.345 \\
\hline Mean \pm SD & \multicolumn{5}{|l|}{} \\
Range & $\begin{array}{c}104.04 \pm 14.3 \\
53-143\end{array}$ & 0.325 & 0.746 \\
\hline Height: & $55-144$ & & 0.348 & 0.729 \\
\hline Mean \pm SD & $\begin{array}{c}18.4 \pm 2.74 \\
10-24\end{array}$ & & \\
Range & $18.14 \pm 2.85$ & $10-25$ &
\end{tabular}

Table (3) showed that there was a significant difference between the two studied groups as regard developmental milestones, verbal IQ, performance IQ and total IQ.

Table (3): Comparing early developmental milestones and intelligence quotient (IQ) of children who were breastfed versus those artificially fed

\begin{tabular}{|c|c|c|c|c|c|c|}
\hline \multirow[t]{2}{*}{ Variable } & \multicolumn{2}{|c|}{$\begin{array}{c}\text { Breastfed } \\
(n=28)\end{array}$} & \multicolumn{2}{|c|}{$\begin{array}{l}\text { Artificial-fed } \\
\qquad(n=28)\end{array}$} & \multirow[t]{2}{*}{$\chi^{2}$} & \multirow[t]{2}{*}{$P$ value } \\
\hline & No. & $\%$ & No. & $\%$ & & \\
\hline \multicolumn{7}{|c|}{ Developmental milestones: } \\
\hline Normal & 27 & 96.4 & 19 & 67.9 & 7.96 & $<0.05$ \\
\hline Delayed motor & 0 & 0.0 & 3 & 10.7 & & \\
\hline Delayed language & 1 & 3.6 & 6 & 21.4 & & \\
\hline \multicolumn{7}{|c|}{ Intelligence Quotient (IQ) } \\
\hline \multicolumn{5}{|c|}{ Verbal IQ: } & T test & P value \\
\hline Mean \pm SD & \multicolumn{2}{|c|}{$61.3 \pm 7.4$} & \multicolumn{2}{|c|}{$56.4 \pm 6.6$} & 2.615 & $<0.05$ \\
\hline \multicolumn{7}{|l|}{ Performance IQ: } \\
\hline Mean \pm SD & \multicolumn{2}{|c|}{$50 \pm 5.5$} & \multicolumn{2}{|c|}{$46.6 \pm 3.3$} & 2.805 & $<0.01$ \\
\hline \multicolumn{7}{|l|}{ Total IQ: } \\
\hline Mean \pm SD & \multicolumn{2}{|c|}{$107.9 \pm 9.1$} & \multicolumn{2}{|c|}{$100.5 \pm 7.7$} & 3.285 & $<0.01$ \\
\hline
\end{tabular}

Table (4) showed that there was a strong positive significant correlation between breastfeeding and verbal IQ, performance IQ, and total IQ. While there was non-significant negative correlation between artificial feeding and verbal IQ, performance IQ and total IQ.

Table (4): Correlation between breast feeding and other variables

\begin{tabular}{|l|c|c|}
\hline \multicolumn{1}{|c|}{ Correlation } & r & P \\
\hline Breast feeding and verbal IQ & 0.534 & $<0.05^{*}$ \\
\hline Breast feeding and performance IQ & 0.562 & $<0.05^{*}$ \\
\hline Breast feeding and total IQ & 0.595 & $<0.05^{*}$ \\
\hline Artificial feeding and verbal IQ & -0.234 & 0.068 \\
\hline Artificial feeding and performance IQ & -0.262 & 0.089 \\
\hline Artificial feeding and total IQ & -0.295 & 0.094 \\
\hline
\end{tabular}

$\mathrm{r}=$ Spearman correlation coefficient 


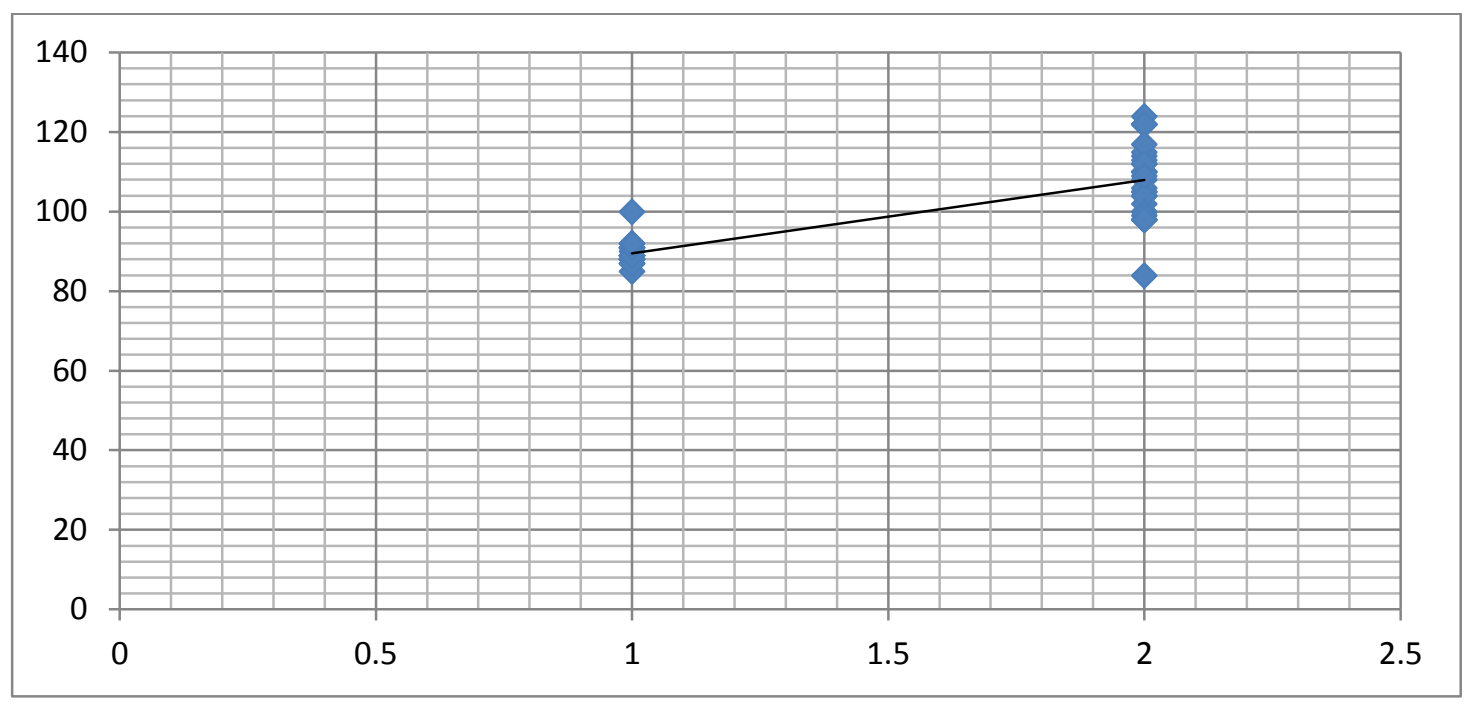

Figure (1): The correlation between breastfeeding and total IQ.

Figure (1), showed that there was strong positive significant correlation between breast feeding and total IQ.

Table (5) showed that breastfed group are 3 to 4 times more likely to have total IQ more than 90 .

Table (5): Feeding pattern as a predictor of IQ

\begin{tabular}{|c|c|c|c|}
\hline Variable & $\begin{array}{c}\text { Odds } \\
\text { ratio }\end{array}$ & $\begin{array}{c}(\mathbf{9 5 \%} \\
\mathbf{C I})\end{array}$ & p-value \\
\hline $\begin{array}{c}\text { Feeding } \\
\text { pattern }\end{array}$ & 3.8 & $2.13-6.75$ & $\begin{array}{c}<\mathbf{0 . 0 5} \\
(\mathbf{S})\end{array}$ \\
\hline
\end{tabular}

\section{DISCUSSION}

The study was conducted as assessment of the effect of the duration of exclusive breastfeeding on cognitive function assessed by the Intelligent Quotient (IQ) test in school aged children who were breastfed in their infancy and to assess differences in intelligence between breastfed and artificial formula-fed children also to detect relationship between type of feeding and cognitive development (Intelligence) in children at school age (6-10 years). The results of this study revealed that there was no statistical significant difference between breastfed group and artificially fed group as regard age and sex of the child. Also, there was no statistical significant difference in order of the child between breastfed groups when compared to artificially fed group.

However, Greene et al. ${ }^{(6)}$ in their study found that first born children were significantly more likely to be breastfed.

There was no statistically significant difference between breastfed and artificially fed groups in the mean age of the mother. However, Ryan ${ }^{(7)}$ found that' women who choose to breastfed tend to be older.

The first breast milk after birth (colostrum) provides the infant with nutrition and immunity ${ }^{(8)}$. Delayed initiation of breast-feeding can lead to hypothermia. One study recorded higher rates of neonatal mortality (pooled odds ratio (OR): 2.02) for those who were breastfed after the first hour of birth compared to those who were breastfed within the first hour of birth ${ }^{(9)}$.

In the research conducted by Acharya and Khanal ${ }^{(\mathbf{1 0})}$, they stated that, in the most recent Nigeria Demographic and Health Survey (NDHS) 2011 survey, the chances of early breastfeeding were higher among mothers with primary education (OR: 1.52) and mothers with secondary or higher education (OR: 2.20) compared to mothers without education. Likewise, the incidence of early breastfeeding among mothers with secondary and higher education was higher in 2006 (OR: 1.66) and in $2001(\mathrm{OR}=1.30)$.

Similar findings have been reported by Khan et al. ${ }^{(9)}$ who reported that non-educated mothers $(72.6 \%)$, mothers with primary education $(63.6 \%)$, secondary education $(65.90 \%)$ and tertiary education $(68.6 \%)$ were also breastfeeding for a prolonged exclusive duration. There was no statistically meaningful association between gross motor milestone growth and length of breastfeeding.

In the case of nocturnal feeding, a statistically significant increase was found in the breastfed group relative to the artificially fed group. The most possible reason is that breastfeeding is much simpler than using the formula when it comes to mixing, heating, cooling and washing the formula, which is difficult at night. The general trend of impaired sleep quality indicated that breast-feeding women showed better subjective sleep quality, but lower normal sleep performance, between four and fourteen weeks after childbirth than artificially fed ${ }^{(11)}$. 
As regards anthropometric measurements of the groups studied, there was no substantial difference between the groups studied in terms of weight, height and high significant difference between the groups studied and the mid-arm circumference in the artificially fed group compared to the breastfed group.

Similar results were published by Marseglia $\boldsymbol{e t}$ al. ${ }^{(12)}$ who found that breastfeeding and its longer length are likely to be correlated with a lower incidence of childhood obesity. Animal milk, but not the recipe. The present research showed that there were no variations in length and head circumference between the sample classes.

Rozé et al. ${ }^{(13)}$ reported similar weight gain in the first 3 months, but breastfed infants increased less rapidly in the remainder of the first year: cumulative weight gain in the first 12 months was $0.65 \mathrm{~kg}$ lower in the breastfed group. The length of benefit was comparable between classes.

As regards the developmental milestones, we have seen a substantial later achievement of motor skills in the artificially fed community relative to the breastfed community.

Evidence linking breastfeeding to early motor development was inconsistent, with some studies suggesting improved motor development in breastfed infants and infants ${ }^{(14)}$ but other studies showed no correlation or, more accurately, no increase in gross motor growth ${ }^{(15,16)}$.

Michels et al. ${ }^{(17)}$ reported that their result in relation to breastfeeding in combination with solid food can be interpreted as gross motor milestone achievement being $7 \%$ faster in these infants than in exclusively breastfed infants at any given age during their 27-months follow-up.

Many studies reported that children who were breastfed perform better in tests of intellectual competence than those who were not. The correlation is seen for full-term babies and more strongly for those who are preterm or low birth weight. The IQ advantage for full-term infants is low, approximately three to four points, but is surprisingly consistent across studies. However, it is not clear if this disparity represents a direct nutritional benefit or a variation in socioenvironmental variables that is more beneficial for breastfeeding women ${ }^{\left({ }^{(18)} \text {. }\right.}$

As far as IQ is concerned, there was a substantially higher IQ in the breastfed children community compared to the artificially fed community. The difference was 11 points in the sample. It is a clear indicator of the importance of breastfeeding and human milk for brain growth. While children who are deprived of their mother's milk have lower neurodevelopmental outcomes. Other workers have reported similar findings and have also shown that the longer the duration of breastfeeding the greater its effects on child's intelligence ${ }^{(19)}$.

There are three substances that may explain the association between breastfeeding and higher scores of intelligence tests. This may be due to the presence of long chain polyunsaturated fatty acids, such as arachidonic acid and docosahexaenoic acid, in breast milk ${ }^{(20)}$. In addition to these properties of breast milk, breastfeeding allows mothers to bond with their infant. These galactolipids are important for the production of the CNS. The amount of lactose in a species milk and the relative size of the brain varies and is the maximum in human milk ${ }^{(21)}$.

Also Victora et al. ${ }^{\text {(22) }}$ found that breastfeeding was positively correlated with IQ, higher education and adulthood income among subjects who have been followed since birth in the southern city of Brazil. Income among subjects who had been breastfed for at least 12 months was $20 \%$ higher than the average, and IQ explained $72 \%$ of the impact of breastfeeding on income.

In contrast, Der et al. (23) found that breastfeeding had little or no effect on children's intelligence. Researchers have found that "Most of the observed association between breastfeeding and cognitive development is the result of maternal intelligence".

\section{CONCLUSION}

Breastfeeding provides superior nutrition for optimum development when exclusive during the first six months of life as shown by the significantly higher IQ in the breastfed group as compared to the artificially fed group of up to 15 points for children breastfed for 6 months and 4 points for those exclusively breastfed for 3 months. Cognitive function of the child is increased with the increased duration of exclusive breastfeeding up to six months of age. Even among the moderate socioeconomic status IQ of those exclusively breastfed for a longer duration is still higher than the artificially fed with differences of up to 13 points. The education of the mother positively influenced the IQ among children who were exclusively breastfed for 6 months but not the other groups. This may reflect a stronger degree of interactive learning, communication, responsiveness and thereby learning ability in these children.

Conflict of interest: The authors declare no conflict of interest.

Funding sources: The authors have no funding to report. 


\section{REFERENCES}

1. Dauncey MJ (2009): New insights into nutrition and cognitive neuroscience: Symposium on 'Early nutrition and later disease: current concepts, research and implications'. Proc Nutr Soc., 68(4): 408-15.

2. Georgieff MK, Ramel SE, Cusick SE (2018): Nutritional influences on brain development. Acta Paediatr., 107(8): 1310-21.

3. Rieger M, Trommlerová SK (2016): Age-specific correlates of child growth. Demography, 53(1): 241-67.

4. Dobransky KM (2018): Breaking down walls, building bridges: Professional stigma management in mental health care. Soc Ment Health, 9(2): 228-42.

5. Wechsler D (2005): Wechsler intelligence scale for children (4 ${ }^{\text {th }}$ ed.). San Antonio, TX: Psychological Corporation. J Psychoeduc Assess., 25 (3): 285 -92

6. Greene J, Stewart-Knox B, Wright M (2003): Feeding preferences and attitudes to breastfeeding and its promotion among teenagers in Northern Ireland. J Hum Lact., 19(1): 57-65.

7. Ryan AS (1997): The resurgence of breastfeeding in the United States. Pediatrics, 99:12-14.

8. Onalo R (2013): Neonatal hypothermia in sub-Saharan Africa: a review. Niger J Clin Pract., 16(2):129-138.

9. Khan J, Vesel L, Bahl $\mathbf{R}$ et al. (2015): Timing of breastfeeding initiation and exclusivity of breastfeeding during the first month of life: effects on neonatal mortality and morbidity-a systematic review and metaanalysis. Matern Child Health J., 19(3):468-79.

10. Acharya P, Khanal V (2015): The effect of mother's educational status on early initiation of breastfeeding: further analysis of three consecutive Nepal Demographic and Health Surveys. BMC Public Health, 15(1):1069-1073.

11. Tobback E, Behaeghel $\mathrm{K}$, Hanoulle I et al. (2015): Comparison of subjective sleep and fatigue in breastand bottle-feeding mothers. Midwifery, 47: 22-7.

12. Marseglia L, Manti S, D'Angelo G et al. (2015): Obesity and breastfeeding: The strength of association. Women and Birth, 28(2): 81-6.

13. Rozé JC, Darmaun D, Boquien CY et al. (2015): The apparent breastfeeding paradox in very preterm infants: relationship between breast feeding, early weight gain and neurodevelopment based on results from two cohorts, EPIPAGE and LIFT. BMJ Open, 2(2): e000834.

14. McCrory C, Murray A (2013): The effect of breastfeeding on neuro-development in infancy. Matern Child Health J., 17(9): 1680-8.

15. Leventakou $\mathrm{V}$, Roumeliotaki $\mathrm{T}$, Koutra $\mathrm{K}$ et al. (2015): Breastfeeding duration and cognitive, language and motor development at 18 months of age: Rhea mother-child cohort in Crete, Greece. J Epidemiol Community Health, 69(3):232-9.

16. Oddy WH, Robinson M, Kendall GE et al. (2011): Breastfeeding and early child development: a prospective cohort study. Acta Paediatr., 100(7):992-9.

17. Michels KA, Ghassabian A, Mumford SL et al. (2017): Breastfeeding and motor development in term and preterm infants in a longitudinal US cohort. Am J Clin Nutr., 106(6): 1456-62.

18. Damsgaard CT, Ritz C, Dalskov SM et al. (2016): Associations between school meal-induced dietary changes and metabolic syndrome markers in 8-11-yearold Danish children. Eur J Nutr., 55(5): 1973-84.

19. Kramer MS, Aboud F, Mironova E et al. (2008): Breastfeeding and child cognitive development: new evidence from a large randomized trial. Arch Gen Psychiatry, 65(5): 578-84.

20. Horta BL, Loret De Mola C et al. (2015): Breastfeeding and intelligence: a systematic review and meta- analysis. Acta Paediatr., 104: 14-19.

21. Qi C, Sun J, Xia Y et al. (2018): Fatty acid profile and the sn-2 position distribution in triacylglycerols of breast milk during different lactation stages. J Agric Food Chem., 66(12): 3118-26.

22. Victora CG, Horta BL, De Mola CL et al. (2015): Association between breastfeeding and intelligence, educational attainment, and income at 30 years of age: a prospective birth cohort study from Brazil. The Lancet Global Health, 3(4):199-205.

23. Der G, Batty GD, Deary IJ (2006): Effect of breast feeding on intelligence in children: prospective study, sibling pairs analysis, and meta-analysis. BMJ., 333(7575): 945 